2.

DERECHO PROCESAL 



\section{LA NEGATIVA INJUSTIFICADA A LA EXHIBICIÓN DE LA PRUEBA DOCUMENTAL EN EL PROCESO CIVIL CHILENO: UNA SOLUCIÓN EPISTEMOLÓGICA PARA SUPERAR UNA REGULACIÓN DEFICIENTE}

[The unjustifiable denial to disclose documentary evidence in the Chilean civil Procedure: an epistemological solution to overcome a deficient regulation]

\section{IVÁN Hunter Ampuero*}

\begin{abstract}
RESUMEN
El presente trabajo tiene por objeto responder la interrogante acerca de la forma en que las nociones de epistemología jurídica pueden servir para solucionar las hipótesis de frustración de la prueba que se encuentran inadecuadamente regulados por el derecho y que pueden ser sometidos a la discrecionalidad del juez. En especial, se pretende justificar que la ausencia de una regulación eficiente para la recopilación de la prueba relevante en los casos de frustración de la prueba documental y la falta de una norma expresa que así lo disponga, no son im-
\end{abstract}

\begin{abstract}
This work is aimed at answering the question regarding how the legal epistemological notions can be used to solve the hypotheses of spoliation of the evidence that are improperly regulated by the law and that can be subject to the judge's discretion. We hereby especially attempt to justify that the lack of an efficient regulation to gather the relevant proof in cases of destruction of documentary evidence and the lack of a specific norm providing it are not an obstacle, in terms of civil matter, in order to prepare a legal assumption sufficiently
\end{abstract}

RECIBIDO el 24 de marzo y ACEPTADO el 31 de mayo de 2016

* Abogado, Magíster en Derecho U. Austral de Chile, y Doctor en Derecho U. Carlos III, de Madrid, España. Profesor de Derecho Procesal y Litigación Ambiental de la Facultad de Ciencias Jurídicas y Sociales de la Universidad Austral de Chile. Este trabajo fue realizado en el marco y con el financiamiento del Proyecto Fondecyt Regular $\mathrm{N}^{\circ} 1141063$, titulado "Verdades difíciles: Dificultades probatorias en el proceso civil chileno", del cual el autor de este trabajo es su investigador responsable. ivanhunter@uach.cl 
pedimentos en materia civil para elaborar a partir de esa conducta obstructiva una presunción judicial lo suficientemente grave y precisa conforme lo dispone el Art. 426 CPC pare tener por probado un hecho. Para ello se analizan y consideran una serie de elementos claves en la construcción de la inferencia.

\section{Palabras clave}

Derecho probatorio - exhibición de prueba documental - frustración de la prueba . serious and accurate, on the basis of said obstructive conduct and as stipulated in Article 426 of the Code of Civil Procedure to have a fact as proven. To do this, a series of key aspects in the construction of the inference are analysed.

\section{KEYWORDS}

Evidence Law - Disclosure of documents - spoliation of evidence.

\section{EXHIBICIÓN DE DOCUMENTOS-FRUSTRACIÓN DE LA PRUEBA-}

HECHOS DIFÍCIL PRUEBA

\section{INTRODUCCIÓN}

La justicia chilena ha tenido profundas transformaciones en el último tiempo que han permitido sustentar complejas e importantes reflexiones en el ámbito del razonamiento probatorio. Los procesos penal, de familia y laboral han supuesto un cambio importante en la aproximación que el juez tenía sobre los hechos del caso y la prueba. Las reglas de admisibilidad y los sistemas de valoración conforme a la sana crítica, han logrado sacar al juez de su tradicional rol pasivo en la determinación de los hechos, estableciendo estándares exigentes en el razonamiento de las decisiones fácticas en dinámicas de incertidumbre. Esta realidad ha tenido cabida incluso en los sistemas probatorios mixtos -como el actual que rige para el proceso civil patrimonial- que combina las reglas legales de valoración con amplios espacios para la apreciación judicial de las pruebas.

Por otro lado, la recopilación del material probatorio relevante requiere de una regulación que permita a las partes obtener los medios de prueba y la información necesaria para sustentar la pretensión. En nuestro proceso civil la obtención de las fuentes de prueba tiene lugar, por lo general, en una etapa previa, desformalizada, y donde los esfuerzos individuales (incluso los puramente económicos) resultan esenciales para preparar el caso. Sin embargo, no solo el litigante poco o mal informado respecto de los hechos, o con problemas económicos para asumir la carga pecuniaria de la producción de la prueba, tendrá dificultades para levantar las cargas procesales sino también aquel que por alguna circunstancia no tenga ni 
posea los medios de prueba en su esfera de resguardo que le permita su fácil aportación al proceso.

En este contexto parece necesario que el derecho defina reglas claras, y por sobre todo, eficaces para la obtención de la información y la prueba. Esta regulación tiene que hacerse cargo de algo que parece evidente, y que Schauer explicaba muy bien: "que al tratar de averiguar qué sucedió en el pasado, el sistema jurídico debe lidiar con memorias defectuosas, documentos perdidos, testigos ausentes, jurados distraídos y otros incontables impedimentos para saber de manera muy confiable qué tuvo lugar en realidad meses o años antes" ${ }^{\text {. }}$ En este trabajo pretendo hacerme cargo de uno de los inconvenientes que puede enfrentar un litigante en un proceso civil: la indisponibilidad material de un documento que se considera relevante para la decisión del caso, unida a la negativa injustificada de su poseedor de exhibirlo en juicio.

Como se sabe, en nuestro actual CPC la exhibición documental como método de acceso a las fuentes de prueba e información que se encuentran en poder de la contraparte o de terceros, tiene una regulación dispersa. Por una parte, los artículos 273 y 277 se refieren a la exhibición cuando es solicitada en tanto medida prejudicial preparatoria. Por otro lado, el Art. 349 CPC regula la exhibición como medio de prueba, esto es, existiendo un juicio pendiente de decisión. En lo que interesa, las sanciones para que el caso en que el tercero o la contraparte se nieguen injustificadamente a la exhibición, se encuentran contempladas en los artículos 274 y 277 CPC. En el primero, se dispone la aplicación de multas que no excedan de dos sueldos vitales o arrestos hasta de dos meses, determinados prudencialmente por el tribunal, sin perjuicio de repetir a la orden y el apercibimiento. En el segundo, se establece una sanción de carácter procesal dado que el litigante reticente pierde el derecho a hacerlos valer en el juicio, salvo que la otra parte los haga también valer en apoyo a su defensa, o si se justifica o aparece de manifiesto que nos pudo exhibir antes, o si se refieren a hechos distintos de aquellos que motivaron la solicitud de exhibición. Esta última sanción es bastante sui generis, pues nada dice respecto de la suerte que corre aquel hecho que se pretendía acreditar por medio de la prueba negada a exhibir. En la doctrina nacional no existen obras generales o específicas que dediquen mucho tiempo al estudio de las consecuencias a la negativa injustificada.

Quizá uno de los errores conceptuales más notorios en la regulación de la exhibición documental consiste en haberla concebido solo como un deber

${ }^{1}$ SCHAUER, Frederick, Pensar como un abogado. Una nueva introducción al razonamiento jurídico (Madrid, Marcial Pons, 2013), p. 223. 
para el litigante, sin pensar que también puede ser considerada como una verdadera carga procesal ${ }^{2}$. De esta forma el litigante que no cumple con la exhibición puede ser compelido al cumplimiento del deber, pero en ningún caso la expectativa de obtener un resultado favorable en el juicio sufrirá una merma. El legislador reacciona disponiendo mecanismos coercitivos - de dudosa constitucionalidad y de escasa utilización práctica- para que el litigante en cuyo poder se encuentra el documento produzca su exhibición en el proceso, pero no sanciona esa inactividad con alguna consecuencia procesal concreta que pueda colocar en riesgo la estrategia. Esta dinámica, desde la perspectiva de quien pretende triunfar en el juicio, genera incentivos hacia la rebeldía en la exhibición documental, especialmente cuando se trata de un medio de prueba que puede arrojar información fiable y relevante para la determinación de los hechos.

Dado el contexto anterior y frente a la inxistencia de una consecuencia de índole procesal que sea eficaz para lograr la exhibición de la prueba, la pregunta que puede formularse es la siguiente: ¿Qué herramientas dispone la epistemología - de la mano al ordenamiento jurídico- para enfrentar los casos de frustración de la prueba documental? La hipótesis de este trabajo es que la ausencia de una regulación eficiente para la recopilación de la prueba relevante en los casos de frustración de la prueba documental, no es un impedimento para elaborar a partir de esa conducta obstructiva una presunción lo suficientemente grave y precisa conforme lo dispone el Art. 426 CPC para construir "prueba completa" del hecho. El ordenamiento jurídico no prohibe derivar consecuencias probatorias a la negativa de exhibición (desde que no se trata de una norma reguladora de la prueba), y nada impide que el juez en los espacios de discrecionalidad que el permite el razonamiento probatorio pueda elaborar una presunción recurriendo a las nociones de las máximas de la experiencia aceptados por la epistemología jurídica. Esta hipótesis funciona con la siguiente distinción: en aquellos sectores en que el ordenamiento jurídico contempla expresamente un deber de conservación documental exigible a un determinado sujeto es posible derivar consecuencias probatorias a la negativa no justificada a exhibir el documento, estableciendo la verdad del hecho que ha sido objeto de la prueba. Sin embargo, cuando ese deber de conservación documental no existe o se encuentra dispensado, la negativa no justificada no resulta suficiente para la determinación verdadera del hecho.

Para tratar de demostrar la hipótesis de trabajo seguiré el siguiente ca-

${ }^{2}$ Esta es una discusión bien ardua en el derecho comparado, pues es cierto que la orden judicial de exhibición documental no produce el efecto de la carga levantada o satisfecha. Véase: Michelli, Gian, La carga de la prueba (traducción de Santiago Sentis Melendo, Bogotá, Temis, 2004), p. 139. 
mino: en primer lugar (II) haré referencia a la frustración de la prueba en el proceso civil por considerar que la negativa injustificada se encuentra en una de dichas hipótesis; luego (III) se exponen las diferentes fórmulas que en el derecho comparado y nacional se han elucubrado para dar cuenta de las formas en que se puede obtener la información difícil, no sin antes dar una revisión del discovery norteamericano y disclosure inglés. Posteriormente (IV) he querido hacer explícita la máxima de la experiencia utilizada, defendiendo su validez en tanto representa una síntesis de un conocimiento socialmente aceptado. En la parte (V) me preocupo de indicar los elementos que sirven al juez para la construcción de una presunción grave y precisa en el caso de frustración de la prueba. Termino con las conclusiones (VI).

\section{Frustración DE LA PRUEBA EN EL PROCESO CIVIL CHILENO}

La negativa injustificada de exhibir los documentos en el proceso civil puede insertarse en un contexto más general, que se podría denominar frustración de la prueba por uno de los litigantes, generalmente el que tiene en su poder el medio probatorio o cuenta con el acceso al mismo. Entiendo por frustración de la prueba la situación que se produce cuando "un litigante dolosa o negligentemente destruye, inutiliza, impide o, de cualquier modo, frustra pruebas que la parte contraria necesitaba para hacer prosperar sus pretensiones"3. La frustración de la prueba puede admitir diversas modalidades. Puede ser total o parcial según se inutilice toda la prueba disponible o una parte de ella; dolosa o negliente, según si concurre algún elementos intencional; también puede ser anterior o durante el proceso. Cualquiera sea la modalidad de producción y su alcance, las consecuencias son idénticas, en la medida que eliminan un elemento probatorio que puede servir de respaldo de las hipótesis fácticas en concurso ${ }^{4}$.

Evidentemente que la frustración de la prueba afecta de manera inmediata el derecho a la prueba que ostentan todos los ciudadanos que recurren a un tribunal de justicia. Este derecho les permite ofrecer, incorporar y

${ }^{3}$ Ormazabal, Guillermo, Carga de la prueba y sociedad en riesgo (Madrid, Marcial Pons, 2004), p. 54.

${ }^{4}$ La frustración de la prueba es una categoría jurídica que debe distinguirse de la aplicación del principio de adquisición procesal en la hipótesis en que una de las partes logra la admisión de un determinado medio de la prueba que luego no practica, frustrando la expectativa que la otra parte se había realizado respecto de la información que podía arrojar ese medio. Para Muñoz Sabaté, en cambio se trata de una situación que puede asimilarse cuando el proponente de la prueba se desiste cuando advierte un sesgo desfavorable. MuÑoz, Luis, Técnica probatoria. Estudios sobre las dificultades de prueba en el proceso (Bogotá, Temis, 1997), p. 481. 
prácticar todos los medios de prueba de que tengan conocimiento y puedan ayudar a la obtención de su pretensión. Cuando un litigante impide la práctica de la prueba, o simplemente se limita a no cooperar en su realización (siendo ésta fundamental para el éxito de la misma), se produce una verdadera lesión al derecho a la prueba ${ }^{5}$. Por eso, los ordenamientos jurídicos deberían tener una regulación que permita, por un lado, asegurar la práctica de la prueba que pueda desparecer, y por el otro, contener mecanismos -con influencia en el resultado del proceso- que actúen frente a las hipótesis de frustración de prueba.

Nuestro Código de Procedimiento Civil de 1903 no conoció la noción ni el concepto de la frustración de la prueba, ni siquiera para el caso de la exhibición documental, cuya negativa solo se sanciona con multas, arresto y la imposibilidad de hacer valer el documento no exhibido en juicio (Arts. 274 y 277 CPC). No hay tampoco alguna disposición con capacidad de hacerse cargo, con efectos netamente procesales, de los casos en que la parte que tiene acceso o a su disposición una prueba se niega injustificadamente a colocarla a disposición del tribunal.

Lo que sí reguló, de manera bastante inconsistente e insuficiente, es el aseguramiento de la prueba, a través de las denominadas medidas prejudiciales preparatorias y probatorias desde los artículos 273 a 289 CPC $^{6}$. La regulación de esta institución es inconsistente desde que solo opera en la etapa previa a la entrada en juicio, sin que se pueda asegurar la prueba

${ }^{5}$ Derecho a la prueba que de acuerdo a la doctrina tiene cuatro componentes prácticamente indiscutidos: a) derecho a utilizar todos los medios de prueba; b) derecho a que las pruebas sean practicadas; c) derecho a que las pruebas sean valoradas racionalmente, y, d) el derecho a la motivación de la sentencia. Véase: Ferrer, Jordi, La valoración racional de la prueba (Madrid, Marcial Pons, 2007), pp. 54 a 59. Una sentencia de la Corte de Apelaciones de Talca fue muy clara en justificar la negativa a conceder la exhibición de documentos como medio de prueba con un caso de indefensión: "Se acoge el recurso, toda vez que al acoger el sentenciador el recurso de reposición deducido por la parte ejecutante, y negar lugar a la exhibición de los documentos, se ha dejado a la parte ejecutada en la indefensión, impidiéndole probar sus excepciones en el juicio. En efecto la solicitud de exhibición de documentos planteada por la parte ejecutada se enmarca dentro del derecho que le concede el artículo 349 del Código de Procedimiento Civil respecto de documentos que se encuentran en poder de la parte ejecutante, y tal diligencia probatoria tiene relación directa con la cuestión debatida en virtud de las excepciones opuestas por dicha parte, no revistiendo los referidos documentos el carácter de secretos o confidenciales según se desprende de la relación que de ellos se realiza en el respectivo escrito". C. Talca, 2 de abril de 2015, Rol N¹08-2014.

${ }^{6}$ Estas medidas en el derecho comparado se conocen con el nombre de diligencias preliminares, y tienen una regulación mucho más extensa. Véase: BANAClOCHE, Julio, Diligencias preliminares (Madrid, Thomson-Civitas, 2003), pp. 31 y ss. 
una vez que el proceso comienza. Esto, desde luego, hace que esta institución sea bastante ineficiente. Por otra parte, la regulación también es insuficiente dado que solo hace referencia a casos específicos y precisos (inspección del tribunal, y prueba pericial en el Art. 281, la testimonial en el Art. 286, y confesión en el Art. 284, todos los CPC), sin que exista una norma general o de clausura que permita incorporar otras situaciones dentro de estas medidas. De esta forma si se requiere asegurar la prueba, pero la situación o caso no se encuentra regulado, no será posible recurrir a las medidas prejudiciales preparatorias.

Evitar la pérdida, ocultación o destrucción de las fuentes de prueba constituye un bien o valor que el ordenamiento intenta perseguir incluso sobre otros derechos constitucionalmente protegidos. Es el caso del proceso penal, donde en el Art. 140 letra c) CPP, permite al juez decretar la prisión preventiva cuando "es indispensable para el éxito de diligencias precisas y determinadas de la investigación". Agrega posteriormente que "Se entenderá especialmente que la prisión preventiva es indispensable para el éxito de la investigación cuando existiere sospecha grave y fundada de que el imputado pudiere obstaculizar la investigación mediante la destrucción, modificación, ocultación o falsificación de elementos de prueba; o cuando pudiere inducir a coimputados, testigos, peritos o terceros para que informen falsamente o se comporten de manera desleal o reticente"7. De esta forma, el ordenamiento jurídico priva al imputado de su libertad cuando existen antecedentes que permitan inferir que éste realizará maniobras destinadas a manipular o desaparecer las pruebas. Se trata de una medida grave, pero que se justifica en la efectividad de la persecución penal.

Evidentemente que una norma como ésta no puede tener un correlato en el proceso civil, pero las situaciones en que una de las partes realiza la destrucción u ocultación de un medio de prueba, o simplemente la frustra, también pueden suceder. Esto desde luego debería asumirse como un dato cierto en el proceso civil; sin embargo, el legislador solo se hace cargo del aseguramiento de la prueba en la etapa prejudicial (y de manera bastante defectuosa) pero nada dice de los efectos o consecuencias para el caso de negativa injustificada a la exhibición o frustración de la prueba.

En el Proyecto de Código Procesal Civil se contempla una regla en el

${ }^{7}$ Cabe indicar que esta norma debiese relacionarse con el Art. 269 ter del Código Penal, que dispone: "El fiscal del Ministerio Público, o el abogado asistente del fiscal, en su caso, que a sabiendas ocultare, alterare o destruyere cualquier antecedente, objeto o documento que permita establecer la existencia o inexistencia de un delito, la participación punible en él de alguna persona o su inocencia, o que pueda servir para la determinación de la pena, será castigado con presidio menor en cualquiera de sus grados e inhabilitación especial perpetua para el cargo". 
Art. 309 inciso $6^{\circ}$, que permite al juez "dar por acreditados los hechos que se pretenden probar con la exhibición de documentos que se encuentran en poder de la contraparte, si esta injustificadamente no cumpliere con este deber en los términos y oportunidad señalados por el tribunal, habiéndosele apercibido en ese sentido en la resolución que hubiera ordenado la diligencia”. Esta norma es genuina en nuestro derecho y constituye un complemento indispensable para la diligencia de exhibición documental, y la eficacia del actual sistema procesal civil ${ }^{8}$. Con todo, es evidente que su aplicación generará problemas prácticos interesantes, puesto que siguen estando al arbitrio iuris la determinación de los efectos probatorios?.

\section{III. ¿CÓMO EVITAR O ENFRENTAR LOS CASOS DE FRUSTRACIÓN DE LA PRUEBAS?}

La respuesta de cómo enfrentar los casos de frustración de la prueba en el proceso civil dependerá de varias circunstancias. Es evidente que la regulación que postule el legislador estará condicionada por los valores o principios del proceso que estimen prevalentes, como también por los derechos constitucionalmente protegidos (debido proceso). En este aspecto se observa quizá la más importante diferencia entre los sistemas del civil y common law.

En la tradición angloamericana la exhibición documental asume con tonos muy diferentes a los sistemas jurídicos del civil law, atendida la diferente concepción del sistema de justicia estatal. Como se sabe, en el proceso civil americano se desarrolla un debate oral y concretado cuya funcionalidad se debe a la existencia de una fase o etapa previa denominada discovery ${ }^{I 0}$, que tiene por finalidad obtener la información que se encuentra en poder del otro litigante, como también solicitar la práctica de cualquiera información o medios de prueba que no está sujeta a reglas de confidencialidad ${ }^{11}$. El propósito de esta etapa es saber qué información

${ }^{8}$ Otra regla, también del PCPC, es la contenida en el Art. 340, que dispone que tanto los terceros como las partes deben de prestar la máxima colaboración para la efectiva y adecuada realización de las inspecciones, reconstrucciones y pericias.

${ }^{9} \mathrm{La}$ redacción de la disposición hace discrecional la determinación de los efectos procesales para el caso de negativa en la exhibición, por lo que será necesario establecer algún criterio de orden general para que el juez pueda utilizarla sin que caiga en una casuística incoherente y arbitraria. Además, lo más probable es que la discusión se traslade o produzca respecto de la justificación de la negativa. En la última parte de este trabajo se darán nociones que pueden orientar esa decisión del juez.

${ }^{10} \mathrm{El}$ Discovery se encuentra desde las reglas 26 a 37 de la Federal Rules of Civil Procedure.

${ }^{11}$ Sobre el discovery y su similar inglés el disclosure, puede verse: TARUfFo, Mi- 
y medios de prueba se cuenta para sustentar un caso en un trial courts of general jurisdiction, definir las posibilidades de éxito y eventualmente evitar el litigio mediante un acuerdo. El discovery se presenta como un momento crucial en un sistema judicial permeado por la eficiencia y la justicia en un máximo esplendor.

A diferencia de los sistemas continentales europeos, donde la intervención judicial aparece esencial para que los litigantes manifiesten la información relevante y acompañen los medios de prueba, el discovery americano se desarrolla directamente entre los abogados y clientes. Existe, -al menos en su primera etapa- una prescindencia de la intervención de los jueces. Amen a una cultura jurídica impregnada de las buenas prácticas y que privilegia los acuerdos como una forma de justicia eficiente, el sistema americano reprime fuertemente las actuaciones maliciosas que se producen en el marco del discovery, disponiendo penas graves e incluso la dictación de sentencias sin forma de juicio para quien haya actuado maliciosamente ${ }^{12}$.

Por lo general la exhibición de documentos propia de los sistemas del civil law esta opera con el prisma del medio de prueba, esto es, cada litigante solicitará la exhibición e incorporación al proceso de los documentos sobre los que tenga una expectativa razonable de que les producirán un resultado favorable para el juicio ${ }^{13}$. En el discovery, en cambio, la pretensión exhibitoria no solo está relacionada con la obtención del material probatorio o hechos relevantes que puedan apoyar una determinada demanda, sino además evitar las pruebas y los hechos sorpresivos (unfair surprise) que se ignoraban y no se tenía conocimiento anticipadamente. Esta diferencia apunta a la particular concepción con que el derecho selecciona las metodologías para la aproximación al conocimiento judicial de los hechos.

En un sistema procesal coherente las consecuencias de la negativa in-

chele, El proceso civil adversarial en la experiencia americana. El modelo americano del proceso de connotación dispositiva (Bogotá, Temis, 2008), pp. 8 a 16; PEREIRA, Silvia La exhibición de documentos y soportes informáticos en el proceso civil (Navarra, Thompson Reuters, 2013), pp. 229 a 239; De la Prada Rodríguez, Mercedes, y Muñoz, Roberto, El proceso civil inglés (Granada, Editorial Comares, 2014), pp. 110 y ss. Hollander, Charle, Documentary disclosure: lessons from the English experience, en In The Future of Transnational civil litigations (Londres, Britisch Institute of International and Comparative Law, 2004), pp. 151 y ss., STÜRnER, Rolf, Derecho Procesal y culturas jurídicas en Ius et Praxis 13 (2007), pp. 435 a 462; y ANSANELLI, Vicenzo, Comparazione e ricomparazione in tema di expert witness testimony, en Rivista di Diritto Processuale, 64 (2009), p. 721.

${ }^{12}$ Pereira, Silvia, cit. (n. 12). p. 237.

${ }^{13}$ Como afirma Damaska la elección del material de información estará guiado por criterios o deseos de ganar el juicio. DAMASKA, Mirjan, El derecho probatorio a la deriva (traducción de Joan Picó i Junoy, Madrid, Marcial Pons, 2015), p. 92. 
justificada a exhibir debiese recaer en el litigante reacio a la colaboración y no respecto de aquel que sufre precisamente esa actitud obstructiva. Un legislador consciente de ello, tiene dos posibilidades regulativas: por un lado, puede invertir la carga de la prueba, disponiendo que la prueba del hecho le corresponde a aquella de las partes que cuenta con los medios de prueba para levantarla; o por el contrario, disponer una presunción simplemente legal que actúe frente a negativa de exhibición, y que permita dar por probado el hecho que constituye la pretensión probatoria.

\section{Reglas especiales de asignación de cargas de la prueba.}

Una de las maneras que el legislador puede utilizar para evitar la frustración de la prueba es modificando la asignación de la carga de la prueba a través de los criterios de disponibilidad y la facilidad probatoria, también conocidas en los ordenamientos latinoamericanos como cargas dinámicas de la prueba o cargas probatorias dinámicas ${ }^{14}$. En este género también es posible encontrar los casos en que el legislador interviene directamente mediante la modificación del objeto de la prueba por medio de las presunciones, que suelen ser utilizadas como mecanismos de nivelación frente a desigualdades sustantivas, y por ende, de facilitación probatoria ${ }^{15}$.

La discusión acerca de estos criterios se ha producido hace bastante tiempo en el Derecho Comparado, especialmente en Italia a través de las presunciones jurisprudenciales ${ }^{16} \mathrm{y}$ en España ${ }^{17}$ con la creación de verdaderos

${ }^{14}$ El término en cuestión se lo debemos en gran parte a las obras del autor argentino Jorge Peyrano, cuyas doctrinales sobre la carga dinámica de la prueba han calado hondo en una buena camada de procesalistas latinoamericano. Detrás de este concepto, se encuentra la idea de solidaridad y responsabilidad compartida de las partes al momento de acopiar el material probatorio. Véase: Peyrano, Jorge, Nueve lineamientos de las cargas probatorias dinámicas, Peyrano, Jorge (director), Cargas probatorias dinámicas (Buenos Aires, Rubinzal-Culzoni, 2004), pp. 19 a 24.

${ }^{15}$ Véase: DenTI, Vittorio, L' inversione dell' prova: rilievi introduttivi, en Rivista Trimestrale di Diritto e Procedura Civile 46 (1992), pp. 709 a 713; Verde, Giovanni, $L$ 'inversione degli oneri probatori nel processo, en Rivista Trimestrale di Diritto e Procedura Civile 46 (1992), pp. 715 a 731; TARuffo, Michele, Presunzioni, inversioni, prova del fatto, en Rivista Trimestrale di Diritto e Procedura Civile 46 (1992), pp. 733 a 756; Cendon, Paolo, y Ziviz, Patrizia, L'inversione dell'onore della prova nel diritto civile, en Rivista Trimestrale di Diritto e Procedura Civile 46 (1992), pp. 757 a 796; Weigmann, Roberto, L' inversione dell' onore della prova nel diritto commerciale, en Rivista Trimestrale di Diritto e Procedura Civile, 46 (1992), pp. 797 a 808; y, FABBRINI, Giovanna, Note in tema di presunzioni legali, en Rivista Trimestrale di Diritto e Procedura Civile, 45 (1991), p. 923.

${ }^{16}$ Por todos, véase: TARUfFo, Michele, La prueba (Madrid, Marcial Pons, 2008), p. 154.

${ }^{17}$ LunA, Álvaro, La prueba de la responsabilidad civil médico-sanitaria. Culpa y 
criterios jurisprudenciales ad hoc de asignación de la carga de la prueba en razón de la cercanía o acceso a la fuente de prueba, especialmente bajo la LEC $1884^{18}$. En los sistemas del common law, en cambio, no se han suscitado mayores discusiones desde que siempre se le ha reconocido a los jueces un poder para fijar la burden of proof de acuerdo a criterios discrecionales. En Chile la discusión se ha iniciado de manera bastante incipiente a propósito del PCPC ${ }^{19}$.

En todos los ordenamientos la asignación de la carga de la prueba conforme a criterios de facilidad y disponibilidad probatoria, busca generar incentivos para que el litigante que tiene a su disposición los medios de prueba los produzca en juicio, más allá si éstos le son procesalmente favorables. Con esta finalidad se faculta al juez para que asigne el onus probandi a una parte distinta de la que aplicando las reglas legales le correspondía, por estar ésta más cercana o tener acceso exclusivo a la fuente de prueba.

Hay consenso en la doctrina que la facilidad como la disponibilidad probatoria considera que una de las partes tiene un mejor acceso a las fuentes de prueba ${ }^{20}$. Sin embargo, conceptualmente es posible y necesario distinguirlos. El principio de facilidad probatoria se aplica cuando los hechos presentan por su especial naturaleza una dificultad en su prueba por quien tiene la carga de hacerlo -le es difícil pero no imposible su prueba- y, en cambio, le resulta mucho más fácil a la contraparte la acreditación del hecho $^{21}$. Esto es particularmente aplicable cuando los hechos del litigio tienen

causalidad (Madrid, Thomson Civitas, 2004), p. 311.

${ }^{18}$ Una cita obligada en el derecho español acerca de la inversión de la carga de la prueba y sus diferentes hipótesis es el trabajo de CorTés, Valentín, Algunos aspectos sobre la inversión de la carga de la prueba, en Revista Iberoamericana de Derecho Procesal, 2-3 (1972), pp. 581 a 639.

${ }^{19}$ Corral, Hernán, Sobre la carga de la prueba en el Proyecto de Código Procesal Civil, en Justicia Civil: perspectivas para una reforma en la legislación chilena (Maite Aguirrezabal G., Editor), Cuadernos de Extensión Jurídica 23, pp. 107 a 117 y PALOMO, Diego, Las cargas probatorias dinámicas: ¿Es indispensable darse toda la vuelta, en Revista Ius et Praxis, 19 (2013), pp. 447 a 464.

${ }^{20}$ FernÁNDEZ, Mercedes, La carga de la prueba en la práctica judicial civil (Madrid, Editorial La Ley, 2006), p. 146; GonZÁLEZ, Piedad, Los criterios de disponibilidad y facilidad probatoria en el sistema del artículo 217 de la LEC, en Carga de la prueba y responsabilidad civil (Valencia, Tirant lo Blanch, 2007) p. 54; ORMAZABAL, Guillermo, cit. (n. 3), p. 21; CoRBAL, Jesús, La adquisición procesal y la carga de la prueba (Madrid, Consejo General del Poder Judicial, 1993) pp. 208 y ss. Recomiendo ver, por lo elocuente y las citas jurisprudenciales: PeLAYo, Ángel, El derecho a la autonomía del paciente en la relación médica. El tratamiento jurisprudencial del consentimiento informado (Granada, Editorial Comares, 2009), pp. 63 y ss.

${ }^{21}$ GonZÁlez, Piedad, cit. (n. 20) p. 55; Fernández, Mercedes, cit. (n. 20), p. 146. 
una naturaleza compleja o técnica ${ }^{22}$. Se englobarían, bajo este principio, los casos en que para una de las partes es más fácil, rápido, fiable, más segura o menos costosa la adquisición y aportación de una prueba ${ }^{23}$. Lo relevante es que la dificultad en la prueba provenga de la especial naturaleza de los hechos y de la posición que la parte gravada con la prueba ocupa respecto de ellos. La facilidad probatoria acerca la carga de la prueba a quien está en mejores condiciones de probar un hecho. No parece, por tanto, ser éste un caso que pueda relacionarse con la negativa a la exhibición documental o frustración de la prueba.

Por otro lado, la disponibilidad probatoria tiene aplicación cuando una de las partes se encuentra en una situación de cercanía, acceso o contacto con la fuente o medio de prueba para acreditar un hecho, lo cual le permite su aportación al proceso sin mayores problemas. Puede ser una facilidad material (un documento) o intelectual (conocimiento de algún dato) ${ }^{24}$. De esta forma, no parece haber duda que el criterio de disponibilidad encuentra absoluta aplicación cuando se trata de instrumentos que se encuentran en poder de la parte no gravada con la carga de la prueba ${ }^{25}$.

Los criterios de facilidad y disponibilidad probatoria como forma ju-

${ }^{22}$ Esteve, José, Técnica, riesgo y Derecho. Tratamiento del riesgo en el Derecho ambiental, (Barcelona, Ariel, 1999) p. 193.

${ }^{23}$ González, Piedad, cit. (n. 20) p. 55; Fernández, Mercedes, cit. (n. 20), p. 147.

${ }^{24}$ Véase: GonZÁlez, Piedad, cit. (n. 20) p. 55; Castillejo, Raquel, La carga de la prueba en el proceso civil por responsabilidad médica, en La Ley, 4 (2006), p. 1713; FernÁndez, Mercedes, cit. (n. 20), p. 158; Montero, Juan, La Prueba en el Proceso Civil (Navarra, Thomson-Reuters, 2005), p. 136; NiEvA, Jordi, La duda en el proceso penal (Madrid, Marcial Pons, 2013), p. 46.

${ }^{25} \mathrm{La}$ jurisprudencia en más de alguna oportunidad ha utilizado soterradamente la inversión de la carga de la prueba cuando la parte que tenía a disposición un medio de prueba idóneo no lo aportó al proceso. Así hizo, por ejemplo, la Corte de Apelaciones de Santiago, en sentencia de 29 de marzo de 1994, que resolvió en contra de una institución bancaria por no proporcionar información que solo ella poseía y que demostraría la procedencia e improcedencia de la excepción opuesta (C. Santiago, 29 de marzo de 1994, MJCH_MJJ1887). La Corte Suprema, no obstante, ha rechazado la aplicación de la inversión de la carga de la prueba cuando el actor no ha solicitado la exhibición del respectivo documento, esto es, cuando no agotó los medios disponibles para procurarse la prueba (C. Suprema, 20 de enero de 2011, Rol No62492010. Queda la duda de cuál habría sido el argumento utilizado por la Corte en el supuesto de que el litigante haya solicitado la exhibición del documento y ésta no se hubiese logrado). Hay ocasiones en que la misma jurisprudencia ha actuado en base a razonamientos en los que subyacen dificultades probatorias derivadas del acceso y posición que una de las partes tiene respecto de la prueba. Y lo ha hecho, precisamente, para reafirmar el papel crucial que juegan las presunciones de construcción jurisprudencia. C. Suprema, 23 de enero de 2012, Rol 4699-2011. 
dicial de asignación de la carga de la prueba han recibido diversas críticas. La principal se relaciona con la vulneración de normas del debido proceso, muy especialmente con el derecho de defensa de litigantes que se verían sorprendidos al momento de la decisión final con el cambio en la asignación de la carga probatoria. La falta de información previa por parte del juez acerca del criterio de decisión final del hecho incierto constituye el principal escollo para aceptar esta forma de enfrentar las dificultades probatorias ${ }^{26}$.

Otra de las críticas cuestiona otorgar a los jueces una potestad discrecional para manipular las cargas probatorias de acuerdo a circunstancias que se consideren justas en el caso concreto. Los jueces no deberían intentar modificar la regulación sustantiva por medio de las cargas de la prueba cuando sospechen que la decisión así adoptada será injusta. En este sentido la función del derecho es prever criterios generales, seguros y previsibles para la decisión final, impidiendo una decisión ad hoc solo válida para un caso específico ${ }^{27}$.

\section{Valoración de la conducta procesal.}

La valoración de la conducta procesal de las partes constituye un tópico poco explorado en el derecho nacional y comparado. Solo hace un par de años, la doctrina ha comenzado a generar algunas reflexiones en torno al valor probatorio que podría asignarse a las conductas desplegadas por la partes en el proceso civil, especialmente para las situaciones de difícil prueba $^{28}$. El CPC no consagra con la misma fuerza que el PCPC una norma de carácter general que permita al juez valorar la conducta procesal de las partes, aun cuando existen algunas disposiciones que pueden servir como referencia para establecer algún criterio de aplicación más amplia.

Los ejemplos se refieren a la confesión judicial ante la incomparecencia de la parte citada a prestarla en segunda oportunidad, la que es tenida como reconocimiento de los hechos categóricamente afirmados en el pliego de posiciones (Art. 394 CPC). O la hipótesis del Art. 313 CPC que considera como aceptación la no contradicción sustancial y pertinente de los hechos contenidos de la demanda. Una disposición particularmente relevante en la materia es el Art. 724 CPC, ubicada en el juicio de mínima cuantía, que establece: "la prueba se apreciará en la forma ordinaria. Pero podrá el tribunal, en casos calificados, estimarla conforme a conciencia, y según la

${ }^{26}$ Corral, Hernán, cit. (n. 19), p. 111; Palomo, Diego, cit. (n. 19), pp. 457 y 458, y PeyRano, Jorge, La doctrina de las cargas probatorias dinámicas y la máquina de impedir en materia jurídica, Peyrano, Jorge (director), Cargas probatorias dinámicas (Buenos Aires, Rubinzal-Culzoni, 2004), pp. 80 y ss.

${ }^{27}$ TARUfFo, Michele, cit. (n. 15), p. 154.

${ }^{28}$ MuÑoz, Luis, cit. (n. 4), pp. 449 a 489, en especial, pp. 472 a 486. 
impresión que le haya merecido la conducta de las partes durante el juicio y la buena o mala fe con que hayan litigado en ée'. Se trata de la única disposición en el CPC que hace referencia expresa a la conducta procesal, refiriéndola solamente a la apreciación de la prueba. Bien aplicada, esta disposición tiende a aminorar el rigor de las reglas de valoración legal cuando es posible observar alguna conducta contraria a la buena fe procesal, y según alguna antigua jurisprudencia subyace la sana crítica en esta forma de valoración de la conducta ${ }^{29}$.

En otra parcela del derecho, como en el de familia, la negativa injustificada a someterse al examen biológico de ADN permite al juez presumir la paternidad, valorando la conducta reticente y poco colaboradora del demandado frente a la práctica de la prueba pericial ${ }^{30}$. En materia penal, por el contrario, derivar consecuencias probatorias de la conducta del imputado en el juicio no está permitido en la medida que tiene derecho a guardar silencio, y tampoco tiene el deber o carga de aportar los medios de prueba.

Resulta particular la situación del sistema italiano en relación a la

${ }^{29}$ C. Santiago, 7 junio 1993 . R., t. 90 , sec. $3^{\circ}$, p.103, dijo: “Los sentenciadores estiman que uno de los elementos que integran el concepto de la sana crítica, con arreglo al cual debe emitirse el juzgamiento, es el principio de derecho contenido en el artículo724 del Código de Procedimiento Civil, en cuanto incorpora al proceso, que lleva a formar la convicción de los falladores, el análisis de la conducta de las partes durante el juicio y de la buena o mala fe con que hayan litigado; lo que, en el caso del actor, que ante la Inspección del Trabajo reclamó sólo desahucio e indemnización y al deducir demanda agregó a la anterior otras pretensiones adicionales, determina que las situaciones dudosas deban resolverse en contra de las pretensiones del actor".

${ }^{30} \mathrm{La}$ Corte de Apelaciones de Santiago, en sentencia de 9 de agosto de 2013, Rol No 17-2013, explicitó claramente la máxima de la experiencia que se encontraba presente en la presunción legal: "que del análisis del artículo 199 del Código Civil, queda de manifiesto que actualmente el legislador contempla la negativa injustificada de las partes a practicarse el peritaje de rigor como una sanción, a quien con su actitud reticente revela una conducta contraria al esclarecimiento de la verdad, por lo que sólo basta que la situación de hecho prevista en la norma concurra, cuyo es el caso de autos, para que dicha presunción opere sin mayores exigencias, ya que de lo contrario, atendido la difícil que resulta la prueba de la paternidad, se estaría favoreciendo al litigante que obra de mala fe, lo que no se condice en ningún caso con el tenor literal de la citada disposición legal, ni con la intención que el legislador tuvo al modificar su redacción”. La jurisprudencia también ha sancionado la falta de cooperación en el ámbito de la aportación de la prueba, valorando la conducta del sujeto que no proporciona la prueba que está a su disposición. Así, también en Corte de Apelaciones de Concepción, de 8 de septiembre de 2010, Rol N²030-2009, donde valora concretamente la falta de cooperación del Hospital Naval en proporcionar los antecedentes y nombres de las personas que atendieron a la actora. 
valoración de la conducta de las partes. En el derecho italiano existe una disposición expresa (Art. 116 inciso $2^{\circ}$ Codice di Procedura Civile $e^{31}$ ) que permite al juez inferir "argumentos de prueba" por la conducta de las partes frente a la práctica de ciertos medios de prueba o en general de su actitud en el proceso. Aquí se sostiene que esta conducta puede ser considerada una fuente de prueba (es decir, un elemento informativo que sirve para determinar la verdad de un hecho), pero con un grado de validez epistémico menor que el resto de los medios probatorios ${ }^{32}$. Esto significa que la conducta o actitud de la parte solo puede servir para reafirmar la existencia de un hecho, que ha sido medianamente establecido por otros medios probatorios, pero en caso alguno sirve por sí sola para determinarlo ${ }^{33}$. El juez solo podría servirse de los argumentos de prueba (conducta de la partes) para completar e integrar la valoración de una prueba propiamente tal, pero en ningún caso para operar frente a la falta de prueba y menos aun para contrastar el éxito de una prueba en sentido estricto ${ }^{34}$.

Vincular efectos probatorios a la conducta de las partes no ha estado exento de críticas. Por un lado, se puede cuestionar la máxima de la experiencia utilizada, puesto que se trata de una máxima espuria que carece de confirmación empírica o científica ${ }^{35}$ y que tiene aplicación en la sentencia

${ }^{31}$ Art. 116 inciso $2^{\circ}$ "Il giudice può desumere argomenti di prova dalle risposte che le parti gli danno a norma dell'articolo seguente, dal loro rifiuto ingiustificato a consentire le ispezioni che egli ha ordinate e, in generale, dal contegno delle parti stesse nel processo".

${ }^{32}$ Carrara, Antonio, Prova e convincimento del giudice nel processo civile, en Rivista di Diritto Processuale, 1 (2003), p. 57; Ricci, Gian, Prove e argomenti di prova, en Rivista Trimetrale di Diritto e Procedura Civile, 47 (1988) pp. 1036 y ss.; RuffinI, Giuseppe, Argomenti di prova e fondamento della decisione del giudice civile, en Rivista Trimetrale di Diritto e Procedura Civile, 58 (2004), p. 1329 y ss.; ConTe, Mario, La prove civile (Milán, Giuffrè Editore, 2005), p. 7.

${ }^{33}$ Véase, con una buena síntesis, las posiciones que existen acerca de los argumentos de prueba en: Comoglio, Luigi, Ferri, Corrado, y Taruffo, Michele, Lezione sul processo civile, (Bolonia, Il Mulino, 1995), p. 655 y Scalamogna, Margherita, L'efficacia probatoria degli argomenti di prova, en Rivista di Diritto Processuale, 64 (2005), pp. 1161 a 1165. Las dos tesis que se sostienen en el derecho procesal italiano son: por un lado, aquella que excluye que los argumentos de prueba sean por sí solo idóneos para fundar la determinación de un hecho, afirmándose que se trata de elementos de juicio accesorios, secundarios y no dotados de autónoma eficacia. La jurisprudencia italiana, en cambio, es algo menos rigurosa, aceptando que la prueba de un hecho quede determinada mediante argumentos de prueba cuando son particularmente claros y significativos.

${ }^{34}$ Comoglio, Luigi, Ferri, Corrado, y Taruffo, Michele, cit. (n. 33), p. 655.

${ }^{35}$ Sobre este tipo de máximas: TARUfFo, Michele, Páginas sobre la justicia civil (traducción de Maximiliano Aramburo, Madrid, Marcial Pons, 2009), p. 444. 
definitiva, sin previa advertencia a las partes ${ }^{36}$. También se ha puesto en duda la validez de la inferencia ${ }^{37}$.

En todo caso, la ausencia de algún estudio específico que pueda ayudar en la tarea de los jueces ha sido uno de los principales motivos por el que la valoración de la conducta procesal de las partes sigue estando ajena a las fuentes de prueba que puede servir de información útil y relevante para la determinación de un hecho.

\section{Reglas de la buena fe procesal}

Otra forma que también se ha utilizado para lograr la colaboración de las partes en el proceso civil es la buena fe, cuya realización permitiría originar deberes procesales ${ }^{38}$, estableciendo conductas que se conformen con su contenido ${ }^{39}$. Emergería así un deber de colaboración, que tendría su manifestación más evidente en la agregar al proceso todos los medios de prueba que se encuentren disponibles y al alcance de la parte. Este deber que se funda en la buena fe procesal precisa un esfuerzo conjunto de las partes para buscar con el juez la justa y pronta solución del litigio ${ }^{40}$.

Una conducta sujeta a criterios de rectitud y honradez socialmente aceptada exigiría el deber de aportar al proceso los medios de prueba necesarios para cumplir con los estándares que demanda la colaboración con la justicia, pues nada más distante con un comportamiento leal es el esconder, negar o silenciar un medio de prueba que puede ser fundamental

${ }^{36}$ BARbosa, Juan, La negativa de la parte a someterse a una pericia médica, en Justicia, Revista de Derecho Procesal. 1-3 (2003), p. 14. 15. Parte de la doctrina, especialmente la italiana después de la reforma al Art. 111 de su Constitución, ha extendido la vigencia del contradictorio como método de formación de la decisión incluso a los argumentos de prueba, esto es, que el juez no puede considerar argumentos de prueba en la sentencia que no hayan sido previamente objeto de debate. Véase: Montesano, Luigi, La garanzia costituzionale del contraddittorio e i giudizi civile di 'terza via', en Rivista di Diritto Processuale, 55 (2000), p. 935 y RiccI, Gian, cit. (n. 32), p. 1088.

${ }^{37}$ Nieva, Jordi, La duda en el proceso penal (Madrid, Marcial Pons, 2013), p. 47.

${ }^{38}$ Véase: CARretta, Francesco, Deberes procesales de las partes en el proceso civil chileno: referencia a la buena fe procesal y al deber de coherencia, en Revista de Derecho Universidad Austral de Chile, 21 (2008), p. 118.

${ }^{39}$ Véase, JimÉnEz Bautista, Susana, La buena fe: perspectiva doctrinal, legal y jurisprudencial. Examen del articulo 247 de la vigente Ley de Enjuiciamiento Civil, en Revista Jurídica Española de doctrina, jurisprudencia y bibliografia, 4 (2003), p. 1562.

${ }^{40}$ Véase: Vallote, Daniel, Abuso del proceso por las partes, presupuestos generales, en XXI Congreso Nacional de Derecho Procesal, Tomo I (San Juan, Universidad Católica del Cuyo, 2001), pp. 274 y 275. En casi idéntico sentido: VaLlejos, Juan, El abuso del proceso en materia probatoria, en XXI Congreso Nacional de Derecho Procesal, Tomo I (San Juan, Universidad Católica del Cuyo, 2001), pp. 737. 
para la correcta adjudicación del juicio ${ }^{41}$. En este contexto parece evidente que los casos de difícil prueba podrían solucionarse recurriendo a la noción de buena fe procesal. La parte que tenga a su disposición los medios de prueba tiene el deber de colocarlos a disposición del juez, más aun cuando la contraparte, inicialmente gravada con la carga probatoria, ha solicitado su exhibición en el proceso. No sería necesario recurrir a mecanismos de alteración de la carga de la prueba.

La buena fe procesal, entendida como fuente de deberes procesales, ha tenido fuertes críticas en la doctrina nacional ${ }^{42}$ y comparada ${ }^{43}$, pues admitir estos deberes supone verificar su compatibilidad con el derecho de defensa, como también su conveniencia y eficacia como mecanismo para recopilar el material probatorio relevante.

En general, sobre lo primero se ha sostenido que pretender fundar en términos amplios deberes endoprocesales sin considerar al proceso como un fenómeno sistémico, conexo e interdependiente, corre el peligro de poner en jaque las garantías constitucionalmente consagradas ${ }^{44}$. En nuestra cultura jurídica, abiertamente impregnada por la disputa judicial, ninguna parte puede ser constreñida a presentar aquellos medios de prueba que no le son convenientes a su pretensión. No se trata, por cierto, de entender que los litigantes tengan derecho a ocultar las pruebas o dificultar su práctica, sino que simplemente no tienen el deber de suministrar la prueba que le corresponde asumir a la contraparte ${ }^{45}$.

Por otro lado, la buena fe por sí sola no es suficiente para generar consecuencias procesales de naturaleza probatoria frente a la conducta negativa del litigante. Resulta evidente, como ya lo he indicado, que el

${ }^{41}$ No obstante la fuerte disputa doctrinal que todavía se mantiene viva, no cabe duda que un deber de colaboración puede ser perfectamente enmarcado dentro de la amplitud del concepto de buena fe procesal. Actúa ética y socialmente correcto quien el litigante que introduce al proceso todos los elementos de convicción necesarios para la dictación de una sentencia justa y colabora con el fin del proceso

${ }^{42}$ Hunter, Iván, No hay buena fe sin interés: La buena fe procesal y los deberes de veracidad, completitud y colaboración, en Revista de Derecho de la Universidad Austral de Chile, 21 (2008), pp. 157 y ss.

${ }^{43}$ LozAno-Higuero, Manuel, La buena fe procesal: consideraciones doctrinales y jurisprudenciales, en El abuso del proceso: mala fe y fraude de ley procesal (Madrid, Consejo General del Poder Judicial, 2006), p. 53, y MonTero Aroca, Juan, Ideología y proceso civil. Su reflejo en la buena fe procesal, en El abuso del proceso: mala fe y fraude de ley procesal (Madrid, Consejo General del Poder Judicial, 2006), p. 281. Pereira, Silvia, cit. (n. 11), p. 91 y ss.

${ }^{44}$ Hunter, Iván, cit. (n. 42), p. 157.

${ }^{45}$ Véase: Calamandrei, Piero: Derecho Procesal Civil, Tomo III (traducción de Santiago Sentis Melendo, Buenos Aires, Editorial Ejea, 1986), p. 259. 
incumplimiento a los deberes procesales es solo objeto de sanciones, generalmente pecuniarias, que no repercuten en el fondo de la decisión. En este sentido, para que los actos que no se ajustan a la buena fe procesal puedan ser sancionados con alguna consecuencia procesal, debe intervenir directamente el legislador creando una presunción, lo que no ocurre en nuestro país. Por otro lado, si el juez quiere construir una presunción a partir del incumplimiento a un deber de buena fe, entonces ésta no juega ningún rol relevante en la inferencia probatoria.

\section{EXHIBICIÓN DE DOCUMENTOS, LA FRUSTRACIÓN \\ DE LA PRUEBA Y MÁXIMAS DE LA EXPERIENCIA: HACIA LA CONSTRUCCIÓN DE LA PRESUNCIÓN JUDICIAL}

He dicho hasta el momento que la hipótesis de frustración de la prueba documental no tiene asignada una sanción especial en nuestro CPC. Ello no es novedad, pues en general, el ordenamiento jurídico nacional se ha encargado de establecer deberes expresos de exhibición documental (directos e indirectos) pero sin establecer sanciones o consecuencias de contenido procesal frente al incumplimiento. Así, por ejemplo, el Art. 5 de la ley 14.908 sobre alimentos dispone que "el juez, al proveer la demanda, ordenará que el demandado acompañe, en la audiencia preparatoria, las liquidaciones de sueldo, copia de la declaración de impuesto a la renta del año precedente y de las boletas de honorarios emitidas durante el año en curso $y$ demás antecedentes que sirvan para determinar su patrimonio y capacidad económica", agregando que en caso que no acompañe todos o algunos de los documentos requeridos, o que presente a sabiendas documentos falsos, será sancionado con las penas del artículo 207 del Código Penal. No hay, por cierto, una sanción de carácter probatoria expresamente asignada por el legislador. Otro ejemplo, también palmario, de la existencia de deberes de exhibición que no se confrontan con consecuencias de carácter procesal es el Art. 29 inciso $1^{\circ}$ de la Ley de Tribunales Ambientales, que obliga a la Administración a acompañar copia autentificada del expediente administrativo completo y debidamente foliado, pero no asigna al incumplimiento de ese deber una sanción expresa.

No obstante, las hipótesis de frustración de pruebas ocasionadas por un litigante o de un tercero que se relaciona o depende de uno de los litigantes, podría perfectamente ser valorada utilizando inferencias probatorias en contra del litigante obstructor ${ }^{46}$. La conexión de estos dos hechos se

${ }^{46}$ Ruffin, Giuseppe, cit. (n. 32), p. 1346; Barbosa, Juan, cit. (n. 36) pp. 14 y 15; PAтTI, Salvatore, Libero convincimento e valutazione delle prove, en Rivista di 
realiza utilizando una máxima de experiencia: "es razonable concluir que, quien se niega o impide el esclarecimiento de unos hechos, lo hace para ponerse a salvo de un perjuicio, en nuestro caso, de las consecuencias jurídicas adversas que le puede acarrear la fijación como ciertos de los hechos en cuestión" ${ }^{47}$. Hay, evidentemente, profundas razones de justicia: "si un litigante impide que el otro levante su carga probatoria, los perjuicios derivados del no esclarecimientos de los hechos no pueden hacerse repercutir en la parte gravada con aquella carga" ${ }^{48}$. Esto ya lo decía Muñoz Sabaté de manera muy clara: "La conducta oclusiva puede presentarse a veces en forma activa, como por ejemplo, mediante la destrucción de instrumentos o de la propia cosa litigiosa. La presunción que se deriva de algunos de los actos de supresión o destrucción de la prueba (...) es siempre desfavorable para el autor, pues partiendo de la base de que un acto de esta clase ha tenido que ser hecho por algún motivo, la lógica inferencia es que fue hecho con propósito de evitar todo cuanto pudiera perjudicar el autor". ${ }^{49}$

Por eso resulta razonable dar por verdadero (o no existente) un hecho cuando los medios de prueba que pueden acreditarlo no son colocados a disposición del tribunal habiéndose así requerido. No hay razones teóricas suficientemente poderosas como para excluir que la prueba del hecho quede establecida por medio de esta presunción judicial, siempre y cuando -obviamente- se trate de inferencias formuladas correctamente, en base criterios epistemológicos adecuado y aceptables, y controlables por medio de una motivación suficiente.

Se trata, en consecuencia, de sacar a la exhibición del ámbito de la regulación del derecho para instalarla en el espacio de la epistemología

Diritto Processuale, 38 (1983), pp. 481-519. Puede verse también: Michelli, Gian cit., (n. 2), p. 146, con referencias a Calamandrei y Carnelutti en el derecho italiano y Goldschmidt, en Alemania.

${ }^{47}$ OrmazABAL, Guillermo, cit. (n. 3), p. 55. En similar sentido para la prueba pericial biológica: BARBOSA, Juan, cit. (n. 36), p. 15 e IgLESIAS, Inés, Intervenciones corporales y prueba de ADN: libre valoración probatoria y argumentación jurídica, en García Amado y Bonorino, Pablo (Coords.) Prueba y razonamiento probatorio en Derecho, Debates sobre abducción (Granada, Comares, 2014), pp. 353.

${ }^{48}$ Ormazabal, Guillermo, cit. (n. 3), p. 59 y Ruffini, Giuseppe, cit. (n. 32), p. 1347. Hasta cierto punto, y retomando lo que más arriba dejé enunciado, la exhibición documental dejaría de ser solo un deber, para compartir algunos rasgos de las cargas procesales. Se trataría, en la nomenclatura de Goldschmidt, de una carga menos perfecta (o imperfecta) desde que los perjuicios de su insatisfacción solo concurren al arbitrio del juez, que en este caso, deberá construir la inferencia probatotria. Véase: Goldschmidt, James, Teoría general del proceso (Barcelona, Editorial Labor, 1936), p. 100.

${ }^{49}$ MuÑoz, Luis, cit. (n. 4), p. 481. 
jurídica. Si entendemos que las reglas de prueba funcionan con una forma de excluir la valoración discrecional del juez de algunos medios de prueba que se estiman relevantes en el contexto de un proceso civil, entonces nada impide que el juez, en aquellos espacios que están fuera del alcance del derecho, puedan utilizar nociones de epistemología jurídica para aproximarse al conocimiento de los hechos.

Con todo, es cierto que la máxima de la experiencia utilizada para construir esta inferencia puede ser tildada de espuria ${ }^{50}$, en la medida que no hay elementos que permitan comprobarla empíricamente, tampoco puede decirse que se base en un prejuicio, estereotipo o que no represente una conexión lógica y poderosa entre dos eventos según el id quo plerumque accidit. Por el contrario, una máxima como ésta representa una síntesis del conocimiento socialmente aceptado en el ambiente social y cultural donde se formula la decisión, no está en contradicción con los conocimientos científicos y no existe una máxima de la experiencia en contrario que pueda anularla ${ }^{51}$. En este sentido, y como lo afirman Anderson, Schum y Twinning, las generalizaciones son peligrosas pero necesarias ${ }^{52}$, y el peligro aquí no consiste en dar por probado un hecho con la versión de la parte que solicita la exhibición del documentos, sino que una de las partes pueda valerse de una conducta obstructiva para limitar el derecho a la prueba de su contraria.

Por otra parte, la máxima de experiencia que se utilizaría en este caso se encuentra implícita en algunas normas jurídicas que hacen referencia casos iguales o al menos parecidos, por lo que se trata de un razonamiento aceptado por el legislador. Así, por un lado, el $453 \mathrm{~N}^{\circ} 5$ inciso $2^{\circ}$ del Código del Trabajo, explica que "Cuando, sin causa justificada, se omita la presentación de aquellos que legalmente deban obrar en poder de una de las partes, podrán estimarse probadas las alegaciones hechas por la parte contraria en relación con la prueba decretada". No cabe duda que en esta disposición, la máxima que conecta el hecho conocido (omitir la presentación de los documentos que deben obrar en poder de alguna de las partes) y el que se declara probado (que son verdaderas las alegaciones hechas en relación a la

${ }^{50}$ TARuffo, Michele, cit. (n. 35), p. 443. También en la doctrina nacional hay quienes opinan que solo las máximas que representan generalizaciones válidas y cuasigeneralizaciones pueden ser utilizadas en la inferencia probatoria. Véase: MATURANA, Javier, Sana Crítica. Un sistema de valoración racional de la prueba (Santiago, Thomson Reuters, 2014), p. 201.

${ }^{51}$ Carratta, Antonio, Funzione dimostrativa della prova, en Rivista di Diritto Processuale, 56 (2001), pp. 95 y 96.

${ }^{52}$ Anderson, Terence; Schum, David; Twining, Williams, Analysis of Evidence, (London, Cambrige University Press, 2005), p. 276. 
prueba decretada) está relacionada con la idea de que el sujeto que entorpece o priva a la otra parte de la prueba documental es porque aquella le genera perjuicios en su contra. Vale lo mismo respecto a la negativa injustificada de someterse al peritaje biológico consagrado en el Art. 199 del CC, dado que si un sujeto no quiere someterse a tal prueba es porque no desea que se sepa la verdad de los hechos. Estas presunciones legales constituyen ficciones que sustituyen la determinación verdadera del hecho cuando el litigante obstaculiza, obstruye o impide la práctica de una prueba, lo que puede ser perfectamente utilizado en el ámbito del razonamiento judicial.

Con todo, es evidente que la justificación de esta máxima de la experiencia debe quedar plasmada en la motivación de la sentencia. En la medida de lo posible es necesario explicitar esta máxima, indicando expresamente cuál es la regla que sirve de pegamento entre el indicio y la conclusión probatoria ${ }^{53}$. Ello permitirá a las partes controlar su grado de fundamento y la probabilidad causal que representan.

\section{ElEMENTOS PARA LA CONSTRUCCIÓN DE UNA PRESUNCIÓN GRAVE Y PRECISA EN EL CASO DE FRUSTRACIÓN DE LA PRUEBA}

Como he dicho antes, de acuerdo al Art. 426 CPC, para que una presunción pueda constituir prueba completa, debe revestir caracteres de gravedad y precisión suficientes ${ }^{54}$. Sin entrar a discutir ni menos a cuestio-

${ }^{53}$ IgARTUA, Juan, Valoración de la prueba, motivación y control en el proceso penal (Valencia, Tirant lo Blanch, 1994), p. 202. Un buen ejemplo de cómo podrían explicitarse esas máximas de la experiencia en una sentencia es el fallo de la Corte de San Miguel, de 12 de enero de 2011, Rol N³93-2010, que enuncia gráficamente la máxima empleada: "es esperable y de normal ocurrencia que si una persona va a realizar una acción que estima urgente y corre a efectuarla, lo haga hasta que complete la acción y por tanto aparece de todo sentido común que el trabajador de autos al momento de percatarse del rebalse del contenido de la máquina que debía operar (lo que quedó acreditado en autos) haya corrido, como lo reseña el testigo Daniel Gómez Marambio, a apagar la máquina, y así se haya desplazado hasta completar la acción, es decir, hasta acabar con la urgencia, apagando o deteniendo la máquina, como es señalado por el recurrente. Asimismo resulta de toda normalidad que un tropiezo o caída se produzca durante una marcha rápida, una carrera y, por el contrario, resulta infrecuente que ocurra en un caminar cuidadoso y pausado. De ello es posible inferir que, de conformidad con lo señalado en el párrafo anterior, el accidente se produjo exactamente en las circunstancias allí descritas". Se podrá o no estar de acuerdo con la máxima empleada, pero la sentencia cumple satisfactoriamente el deber de hacerla explícita.

${ }^{54}$ En el lenguaje decimonónico del CPC de 1903, la expresión plena prueba, semiplena prueba, presunción y base de presunción judicial, constituyen términos difícilmente identificables en el ámbito de las inferencias probatorias, pero justifi- 
nar el lenguaje decimonónico de nuestro $\mathrm{CPC}$ respecto de qué entiende por presunción y por prueba completa, diré que el propósito de las líneas que siguen es intentar precisar los elementos que podrían considerarse por el juez para definir cuándo la negativa a exhibir injustificadamente un determinado documento pueda ser considerada grave y precisa para derivar consecuencias probatorias ${ }^{55}$. Para esa construcción un elemento central y clave es la existencia de un deber de conservación documental. De esta forma, sería posible establecer dos sujetos que pueden quedar gravados con el deber de exhibición: en primer lugar aquel que tenga un su poder un determinado documento, caso en el cual el solicitante deberá aportar los antecedentes necesarios para demostrar tal circunstancia, y, en segundo lugar, el sujeto que tenga la obligación jurídica o legal de conservar un determinado documento ${ }^{56}$, caso en el cual el solicitante no tendría la carga de probar la tenencia.

Hasta cierto punto la tesis que se postula en este trabajo va de la mano con las tendencias modernas en torno al silencio y la rebeldía en el derecho procesal. En efecto, así como en materia de rebeldía se va imponiendo cada vez con mayor frecuencia la ficta confessio, que no es otra cosa que "la posibilidad y necesidad de decidir de acuerdo a lo alegado por la parte diligente" ${ }^{17}$, en materia de negativa injustificada de exhibición documental

cadas en un sistema mixto de valoración de la prueba, en que convivían reglas de prueba legal con espacios de valoración discrecional. El legislador, en este sentido, va graduando anticipada y abstractamente para cada categoría de medio de prueba el grado de verdad que le merecen, empezando por las que solo le sirven -erróneamente- de "base de presunción judicial", pasando por las que hacen "semiplena prueba", y concluyendo por aquellas que constituyen "prueba completa del hecho". Estas últimas no son reglas de valoración sino de decisión acerca de los hechos, desde que la norma jurídica actúa derechamente imponiendo un resultado probatorio completo.

${ }^{55} \mathrm{La}$ gravedad y precisión de esta presunción o inferencia, emana a partir de lo que González Lagier entiende como "acciones intencionales en sentido estricto o dirigidas a fines". Estas se caracterizan porque se dirigen a alcanzar un determinado objetivo e intervienen deseos o creencias de cómo satisfacerlos. En este caso, la decisión del sujeto que se niega a la exhibición documental se encamina a impedir que los efectos de esa prueba puedan ser utilizados en su contra. Dicho en otros términos, el sujeto selecciona la acción u omisión que le permite, en este caso, conseguir un fin, que no es otro que el de evitar las consecuencias procesales de carácter probatorio que puedan derivarse del cumplimiento de la orden de exhibición. Así entonces la negativa a la exhibición es grave porque es una acción adecuada al cumplimiento del fin. Se trata, por tanto, de atribuir una intención a la acción del sujeto que frustra la prueba. Véase, GonzÁlez, Daniel, Quaestio Facti. Ensayos sobre la prueba, causalidad y acción (Bogotá, Temis, 2005), p. 208.

${ }^{56}$ Pereira, Silvia, cit. (n. 11), p. 111.

${ }^{57}$ Orellana, Fernando y Pérez Ragone, Álvaro, Radiografía de la rebeldía en el 
debiese aplicarse el mismo criterio. De esta forma, la exhibición documental debe que ser vista como la oportunidad que tiene el sujeto que ostenta un deber de conservación de probar que aquello que dice o indica como verdadero el solicitante de la medida en realidad no lo es. Se trata, en consecuencia, de complementar la regulación que establece el legislador para la negativa injustificada, añadiendo a los medios compulsivos, una valoración de la omisión estableciendo consecuencias jurídicas concretas ${ }^{58}$.

Dicho lo anterior, a continuación quiero establecer esos elementos o requisitos para que el juez pueda elaborar la presunción:

\section{Existencia de un deber legal de conservación documental.}

Los preceptos legales o reglamentarios que contienen deberes de conservación documental funcionan como respaldos a los hechos probatorios facilitando su determinación en el proceso. Los hechos probatorios constituyen aquellos datos fácticos que deben ser establecidos en el proceso para que el juez pueda realizar la inferencia probatoria, generando como resultado la determinación de otro hecho diferente ${ }^{59}$.

En este sentido, sostengo que existe una estrecha relación entre los deberes de conservación y la exhibición documental. Es evidente que el legislador al disponer expresamente un deber de conservación quiere lograr un determinado efecto que va más allá de la seguridad y certeza, o de permitir un adecuado funcionamiento de una organización público o privada. Los deberes de conservación documental tienen mucho más sentido cuando se les piensa-además-como una forma de aseguramiento de la prueba que el legislador establece para generar resultados probatorios más racionales ${ }^{60} . \mathrm{Y}$ este aseguramiento de la prueba la ley lo coloca en quien tiene más posibilidades y mayor facilidad para conservarlo, ya sea porque operativamente

proceso civil: tópicos hacia una adecuada regulación en la nueva justicia civil, en Ius et Praxis, 12 (2007), p. 20, y pp. 13 a 41.

${ }^{58}$ Respecto a las formas o modos que puede regularse el silencio u omisión en el derecho procesal: CARRASCO, Jaime, La rebeldía en el proceso civil y laboral chileno. Análisis de la rebeldia en los procedimientos ordinario, sumario, ejecutivo y laboral (Santiago, Abeledeo Perrot-LegalPublishing, 2010), p. 40.

${ }^{59}$ GonZÁlez, Daniel, cit. (n. 55), p. 60 y SÁNCHeZ, Pedro, La prueba por presunciones. Particular referencia a su aplicación judicial en supuestos de responsabilidad extracontractual (Granada, Comares, 2007), pp. 11 y ss.

${ }^{60}$ González Lagier afirma de los hechos probatorios que "dada la conexión que existe entre prueba y normas jurídicas para algunos tipos de hechos, nos podemos encontrar no sólo enunciados acerca de la realidad natural o acerca de la existencia de convenciones sociales, sino también enunciados acerca de la existencia de determinadas normas o deberes jurídicos”. GonZÁLEZ, Daniel, cit. (n. 55), p. 60. 
depende de esos documentos -como un Banco, un órgano del Estado, etc.- sea porque le es más fácil conservar los documentos.

No son pocas las parcelas de las relaciones jurídicas en las que es posible encontrar deberes de conservación documental. A continuación pretendo revisar las principales.

a) Juicios contra la Administración del Estado.

En los juicios en que interviene la Administración del Estado -sea como demandante o demandado- también es posible observar ciertos deberes de conservación documental que pueden servir para la construcción de la presunción. Partamos de la base que la Administración y sus órganos manifiestan su voluntad por medio de actos esencialmente escritos, denominados genéricamente actos administrativos (Art. 3 ley 19.880). Estos consisten en instrumentos públicos, en la medida que son dictados por un funcionario público (el que detenta el poder de decisión) y sujeto a ciertas formalidades legalmente previstas. A los actos administrativos, también es posible unir - para estos efectos en una misma categoría- los denominados "documentos no oficiales" como los memorándum, circulares, oficios, ordinarios, y en general a todos lo que no impliquen actos de decisión, juicio o conocimiento.

Sin perjuicio de normativas específicas, la conservación y eliminación de documentos de las instituciones públicas se rige por la Circular $\mathrm{N}^{\circ}$ 28.704, de 1981, de la Contraloría General de la República sobre disposiciones y recomendaciones referentes a eliminación de Documentos, y por la Circular N051, de 2009 de la Dirección de Bibliotecas, Archivos y Museos, Circular sobre disposiciones y recomendaciones referentes a conservación, transferencia y eliminación de documentos. Con respecto a los documentos oficiales de los organismos públicos resulta aplicable el Art. $14 \mathrm{~N}^{\circ} 1$, del DFL N 5200 de 1929, del Ministerio de Educación Pública, que prescribe que deben ingresar al Archivo Nacional los documentos de los Ministerios que hayan cumplido cinco años de antigüedad. El plazo de cinco años constituye la regla general en cuanto a la conservación de los documentos en materia administrativa, con algunas excepciones que se encuentran detalladas en la Circular N²8.704, de 1981, de la Contraloría General de la República. Con todo, aun cuando no exista una norma, los documentos que puedan estar relacionados con un litigio deberán conservarse hasta el término de éste, por la potencial capacidad de servir de medio de prueba.

En este sentido, y tal como se ha afirmado, es posible inferir que si un órgano de la Administración se niega a exhibir un determinado documento habiendo sido requerido al efecto, es porque quiere prevenir consecuencias 
procesales en su contra, pues tiene el expreso deber de conservarlo durante cierto lapso de tiempo.

b) Ley de derechos del paciente.

La ley 20.584, también conocida como Ley de Derecho y Deberes del Paciente, en su Art. 13 dispone: "La ficha clínica permanecerá por un período de al menos quince años en poder del prestador, quien será responsable de la reserva de su contenido. Un reglamento expedido a través del Ministerio de Salud establecerá la forma y las condiciones bajo las cuales los prestadores almacenarán las fichas, así como las normas necesarias para su administración, adecuada protección y eliminación”. Se trata de un específico deber de conservación documental que pesa sobre el prestador del servicio de salud, sujeto a un plazo bastante amplio.

Este deber de conservación de la ficha clínica no solo tiene efectos terapéuticos relevantes, especialmente para aquellos pacientes crónicos sometidos a diversos exámenes, tratamientos, intervenciones y demás prestaciones curativas, sino además netamente probatorias. No cabe duda que el legislador ha dispuesto este deber para asegurar un medio de prueba preconstituido, que contiene información relevante del proceso asistencial del paciente ${ }^{61}$, y que puede ser utilizado como información en un eventual juicio ${ }^{62}$.

\section{c) Bancos e instituciones financieras}

También asoma con tonos interesantes la obligación de conservación documental que pesa a las instituciones bancarias o financieras, desde que

${ }^{61}$ El Art. 12 inciso $1^{\circ}$, de la referida ley define a la ficha clínica como "el instrumento obligatorio en el que se registra el conjunto de antecedentes relativos a las diferentes áreas relacionadas con la salud de las personas, que tiene como finalidad la integración de la información necesaria en el proceso asistencial de cada paciente. Podrá configurarse de manera electrónica, en papel o en cualquier otro soporte, siempre que los registros sean completos y se asegure el oportuno acceso, conservación y confidencialidad de los datos, así como la autenticidad de su contenido y de los cambios efectuados en ella”.

${ }^{62}$ Ahora bien, en las obras más generales que han explorado la prueba de la responsabilidad civil médica en el derecho comparado (especialmente el español) no ha existido un desarrollo muy elaborado acerca de la negativa a exhibir las fichas clínicas. Véase: por ejemplo: Díaz-Regañon, Calixto, El régimen de la prueba en la responsabilidad civil médica. Hechos y derecho (Pamplona, Editorial Aranzadi, 2006), 424 pp., passim; LunA, Álvaro, cit. (n. 17), pp. 616 y ss, passim. No obstante, la doctrina suele reconocer en la historia clínica un valor de prueba especialmente para dejar constancia del consentimiento informado. Véase, Castillejo, Raquel, cit. (n. 24), p. 1733 y Pelayo, Ángel, cit. (n. 20), p. 66. 
contra éstas se sostienen diariamente innumerables controversias jurisdiccionales. Al respecto, el Art. 155 del DFL 3, que fija el texto refundido, sistematizado y concordado de la ley General de Bancos y de otros cuerpos legales que indican, dispone: "Las instituciones sometidas a la fiscalización de la Superintendencia (Bancos e Instituciones Financieras) estarán obligadas a conservar durante seis años sus libros, formularios, correspondencia, documentos y papeletas. El Superintendente podrá autorizar la eliminación de parte de este archivo antes de ese plazo y exigir que determinados documentos o libros se guarden por plazos mayores (...) Podrá, asimismo, facultarlas para conservar reproducciones mecánicas o fotográficas de esta documentación en reemplazo de los originales". Este deber de conservación documental que pese sobre estas instituciones es más palmaria aun cuando se lee el inciso $3^{\circ}$ del Art. 155: "En ningún caso podrán destruirse los libros o instrumentos que digan relación directa o indirecta con algún asunto o litigio pendiente".

Se trata de una norma que obliga a los bancos e instituciones financieras a conservar documentos por un plazo de seis años, es decir, más allá de la prescripción de las acciones ordinarias. La norma es bastante amplia: abarca desde los libros hasta los documentos y papeletas, cubriendo gran parte de la documentación en las que quedan fijadas las operaciones que diariamente realizan estas instituciones. Se dispone además la prohibición de destrucción en el caso de que existan litigios pendientes, extendiendo el deber de conservación hasta la terminación del litigio cuando esta sea superior a los seis años.

De esta manera, existiendo un deber expreso de conservar un determinado documento, su no exhibición injustificada en un juicio por parte del Banco o institución financiera, puede ser atribuida a que la producción de efectos procesales o probatorios negativos que ese documento genera en su detentador.

d) Mantención de documentos contables (tributarios)

También en esta materia tributaria es posible encontrar ciertos deberes de conservación documental. En la legislación tributaria existen diversas reglas que disponen deberes de conservación documental. La regla general para los libros de contabilidad se encuentra contenida en el Art. 17 inciso $2^{\circ}$ del Código Tributario, que dispone: "Los libros de contabilidad deberán ser llevados en lengua castellana y sus valores expresarse en la forma señalada en el artículo 18, debiendo ser conservados por los contribuyentes, junto con la documentación correspondiente, mientras esté pendiente el plazo que tiene el Servicio para la revisión de las declaraciones. Esta obligación se entiende sin perjuicio del derecho de los contribuyentes de 
llevar contabilidad en moneda extranjera para otros fines" ${ }^{33}$. Esta norma se encuentra complementada por el Art. 200 incisos 1 y $2^{\circ}$, que disponen: "El Servicio podrá liquidar un impuesto, revisar cualquiera deficiencia en su liquidación y girar los impuestos a que hubiere lugar, dentro del término de tres años contado desde la expiración del plazo legal en que debió efectuarse el pago (...) El plazo señalado en el inciso anterior será de seis años para la revisión de impuestos sujetos a declaración, cuando ésta no se hubiere presentado o la presentada fuere maliciosamente falsa. Para estos efectos, constituyen impuestos sujetos a declaración aquellos que deban ser pagados previa declaración del contribuyente o del responsable del impuesto".

Esta disposición se encuentra complementada por el Art. 58 inciso $1^{\circ}$, primera parte del DL 852, Ley sobre Impuesto a la Ventas y Servicios, que establece "Los duplicados de las facturas y los originales de las boletas a que se refiere este párrafo deberán ser conservados por los respectivos contribuyentes durante seis años".

Del juego de estas disposiciones se desprende que el deber del contribuyente es de mantener tanto los libros de contabilidad como los documentos que la respaldan ${ }^{64}$ por todo el plazo de revisión y liquidación del impuesto respectivo ${ }^{65}$, que es por regla general de seis años. Este deber de conservación tiene pleno sentido no solo cuando se trata de litigios entre el contribuyente y la Administración (SII) sino además cuando se verifica entre dos contribuyentes, gravados con este deber, pues es de esperar que de solicitarse la exhibición de algunas partes de los libros de contabilidad, o de las facturas o boletas que la respaldan,

2. Determinación del hecho que se pretende probar o el contenido del documento.

Otro aspecto crucial al momento de hacer operativa esta presunción está relacionado con la especificación del hecho que se quiere acreditar por medio de la exhibición de documentos, o en su caso, con la versión del contenido del documento que el solicitante dice que tiene. En el caso del

${ }^{63}$ Según el Art. 25 del Código de Comercio, "todo comerciante está obligado a llevar para su contabilidad y correspondencia: $1^{\circ}$ El libro diario; $2^{\circ}$ El libro mayor o de cuentas corrientes; $3^{\circ} \mathrm{El}$ libro de balances; $4^{\circ} \mathrm{El}$ libro copiador de cartas".

${ }^{64} \mathrm{El}$ SII indica que estos documentos consisten en Los duplicados de las facturas, Facturas de Compra, Guías de Despacho, Liquidación, Liquidaciones-Factura, Notas de Débito y Notas de Crédito y los originales de las boletas deben quedar en poder del emisor, como, asimismo, los originales y triplicados de los mismos documentos que deben quedar en poder del comprador o beneficiario de los servicios (cuando no hayan sido retirados por el SII)

${ }^{65}$ Un sentencia de la Excma. Corte Suprema, de 3 de junio de 2013, Rol No 3265-2012, extendió el deber de conservación para más de seis años tratándose de operaciones. 
derecho español, el Art. 329.1 LEC para el supuesto de negativa injustificada, faculta al juez para atribuirle valor probatorio a la copia simple del documento o a la versión que del contenido se hubiese dado por el solicitante. El Art. $453 \mathrm{~N}^{\circ} 5$ inciso $2^{\circ}$ del Código del Trabajo también supone estimar por probadas las alegaciones hechas por la parte contraria en relación con la prueba decretada.

Esta exigencia resulta especialmente útil cuando el motivo de la exhibición está relacionado con hechos de carácter puramente negativos, esto es, cuando está dirigida a probar la inexistencia de vestigios o huellas de alguna alegación efectuada por las partes en el proceso. En este sentido, el solicitante de la prueba deberá determinar y especificar el hecho o hechos que pretende establecer por medio de la exhibición, de manera que el juez frente a la negativa pueda dar por probado el hecho conforme lo dispone el Art. 426 CPC. Con todo, no debiera ser muy difícil determinar los hechos que se pretenden probar por medio de la exhibición desde que el Art. 349 CPC exige como requisito de su admisibilidad de que éstos tengan relación con la cuestión debatida. Esto supone que la parte deberá justificar en qué medida los hechos que pretende acreditar se logrará por medio de la exhibición documental.

Ahora bien, exigencia cumple funciones adicionales: por un lado, informar a la parte a la que se le solicita la exhibición que los hechos que se pretenden acreditar con el medio de prueba que tiene a su disposición, de manera que pueda asumir las consecuencias procesales de su negativa; y por el otro, definir con precisión qué hechos pueden quedar probados por el juez frente a la negativa, evitando que hechos diferentes a los que se indicaron en la solicitud puedan quedar determinados de esta forma. Esto permite otorgar un grado de certeza a la definición de la presunción, lo que es muy deseado en el contexto de la satisfacción de las cargas procesales.

El momento adecuado para determinar los hechos que se pretenden probar con la exhibición documental es el de la admisibilidad de la prueba. Si el solicitante quiere obtener del juez la decretación de la prueba deberá justificar que los documentos están relacionados con los hechos controvertidos, para lo cual tendrá que indicar qué hechos desea probar y cómo estos documentos sirven como medio de respaldo o confirmación. Ese juicio definirá la admisibilidad de la prueba (relevante y pertinente) y a su vez constituirán el marco que debe ser utilizado por el juez cuando construya la presunción.

\section{Verosimilitud de la existencia del documento y su contenido.}

Una cuestión que parece esencial para que opere esta presunción es que 
la existencia del documento solicitado exhibir sea verosímil ${ }^{66}$. Se trata de un requisito que no está en la ley, pero que tiene un fundamento lógico y que ha sido exigido expresamente desde antaño por la jurisprudencia ${ }^{67}$. Es necesario que exista al menos la apariencia de que el documento existe, para lo cual el solicitante deberá indicar, aunque sea en términos aproximativos, algún dato que permita identificar y hacer plausible su existencia, como por ejemplo su contenido, su fecha, autor, algún otro antecedente en que se haga referencia a la existencia del documento, etc.

\section{Carácter indispensable de la prueba documental.}

Dice relación a que la única o mejor forma de probar el hecho es mediante el documento que se solicita exhibir. El documento debe ser indispensable para la prueba del hecho ${ }^{68}$. Este presupuesto está relacionado con la idea de que los esfuerzos probatorios de las partes no pueden agotarse con la simple negativa a la exhibición, pues sigue siendo hasta cierto punto una fuente secundaria cuando se puede recurrir a una información más fiable y completa. Si la confirmación probatoria del hecho controvertido puede lograrse por medio de otra información entonces la presunción de la que venimos hablando es claramente insuficiente para construir, en el lenguaje del Art. 426 CPC, una presunción precisa y grave.

\section{Inexistencia de prueba en contrario del hecho que se pretende probar} por medio del documento.

Esta es la contrapartida de la univocidad del indicio ${ }^{69}$. Considerar suficiente un indicio para determinar la existencia del hecho, supone

${ }^{66}$ Sobre la verosimilitud y su significado: TARUFFo, Michele, La prueba de los hechos (Madrid, Trotta, 2009), p. 504, y NiEVA, Jordi., Enjuiciamiento prima facie, (Barcelona, Atelier, 2007), p. 12.

${ }^{67}$ La Corte Suprema indicó: "La diligencia de exhibición de instrumentos solicitada de acuerdo con lo prescrito en el artículo 349 del Código de Procedimiento Civil, sólo puede referirse a los que sea verosimil que existan a la fecha en que se ordena la exhibición, pero no a aquellos cuya existencia no consta en forma alguna". C. Suprema, 27 junio 1961 . R., t. 58 , sec. $3^{\circ}$, p. 39.

${ }^{68}$ En el derecho italiano la "orden de exhibición documental" está sujeta a requisitos bastante exigentes. El documento debe ser considerado indispensable para la prueba de un hecho relevante, y el juez tiene que estimar necesaria su adquisición. Según la interpretación mayoritaria, esto significa que debe tratarse de un documento sin el cual la prueba del hecho sería imposible, esto es, es el único medio de prueba disponible sobre aquel hecho. Véase: Comoglio, Luigi, Ferri, Corrado, y TARuffo, Michele, cit. (n. 33), p. 667.

${ }^{69}$ GASCÓN, Marina, Cuestiones probatorias (Bogotá, Universidad Externado Colombia, 2012), p. 56. 
suprimir las otras causas o efectos que lo pueden explicar. Por ello ya no es posible cuando -en el deber de los jueces de realizar una valoración no solo individual sino conjunta de los medios de prueba-, el hecho que se determina probado por medio de la presunción frente a la negativa injustificada puede ser desvirtuado por otros elementos de prueba. Si quien niega la exhibición del documento logra establecer por otros medios de prueba que la versión o contenido del mismo no es el que pretende el solicitante entonces el juez no podrá utilizar esta presunción. Esta es una lógica conclusión del carácter derrotable de las presunciones que, salvo las absolutas o de derecho, siempre admitirán prueba en contrario.

\section{CONCLUSIONES}

La recopilación del material probatorio requiere de una regulación que permita a las partes obtener la información relevante para sustentar sus pretensiones en juicio. Esta recopilación -en los conflictos civiles- se realiza en una etapa previa, de manera privada y desformalizada. Con todo, es posible que no sólo el litigante mal informado o con problemas para satisfacer la carga económica de la prueba tenga dificultades en producir esa información, sino además aquel que por algún motivo esté lejano a las fuentes de prueba o no tenga acceso a las mismas. Para evitar este problema el Derecho debe articular mecanismos eficiencias, capaces de producir consecuencias procesales para el caso que un litigante frustre el acceso a la prueba. Se trata, en consecuencia, de consagrar modos amplios de aseguramiento de la prueba frente al peligro de frustración.

Tratándose de la prueba documental, nuestro legislador reguló la exhibición de manera bastante precaria, al entender, por un lado, que se trata de un deber procesal cuyo incumplimiento puede estar sujeto a sanciones, pero en ningún momento a la disminución de la expectativa de un resultado favorable; y al no disponer consecuencias netamente procesales frente a la negativa injustificada a la exhibición. En los ordenamientos comparados, ligados a los sistemas del common law, la frustración de la prueba puede evitarse mediante herramientas eficientes de Discovery o disclosure, que permiten a las partes valerse de la información relevante antes de entrar a juicio, evitando de esa forma la dispersión y frustración de la prueba. En los sistemas del civil law, en cambio, se han utilizado diversas técnicas y herramientas para sortear los casos de frustración de la prueba, como la inversión de la carga de la prueba, la valoración de la conducta de las partes y la buena fe procesal. Todas estas técnicas han gozado de poderosas críticas que han impedido su consagración general en los ordenamientos. Ahora bien, esa carencia de consecuencias procesales frente a la negativa 
de exhibición es posible salvarla recurriendo a las nociones generales de la epistemología jurídica, con la finalidad de construir una máxima de la experiencia válida que anude a la negativa una consecuencia de carácter procesal. Esta máxima de la experiencia no es otra que aquella que dice que quien niega injustificadamente la exhibición de un documento en juicio, frustrando la prueba de la contraparte, es para colocarse a salvo de una consecuencia procesal desfavorable. De esta manera es posible tener por verdadero el o los hechos que pretendían probarse con el documento negado a exhibir.

Ahora bien, para que esta presunción pueda lograr los caracteres de precisión y gravedad que exige el Art. 426 CPC para constituir plena prueba, debe sortear una serie de requisitos: en primer lugar, la existencia de un deber legal o reglamentario de conservación documental, que funciona en el esquema inferencial como respaldo de los hechos probatorios. En este sentido es posible encontrar una estrecha relación entre deberes de conservación documental y exhibición, dado que el legislador ha dispuesto estos deberes como una forma de asegurar una prueba ante un posible juicio. Las parcelas del Derecho en que se reconoce este tipo de deberes son amplias, cubriendo gran parte de los litigios civiles. En segundo lugar, se requiere precisar el hecho que se pretende probar o el contenido del documento solicitado exhibir. Este requisito permite saber qué hecho resultará probado frente a la negativa otorgando certeza. Es posible dar cumplimiento a este requisito a través de la admisibilidad de la prueba. En tercer lugar, es necesario establecer la verosimilitud de la existencia del documento y de su contenido mediante la indicación de su fecha, autor, contenido, etc. En cuarto lugar, es necesario que el documento resulte indispensable para la prueba del hecho, de manera que el litigante resulte realmente perjudicado con la negativa a exhibir. Por último, para que esta presunción pueda constituir prueba completa del hecho es indispensable que no exista prueba en contrario. Este último requisito dimana del carácter derrotable que tienen todas las presunciones construidas judicialmente.

\section{BibLIOGRAFÍA}

Anderson, Terence; Schum, David; Twining, Williams, Analysis of Evidence, (London, Cambrige University Press, 2005).

Ansanell, Vicenzo, Comparazione e ricomparazione in tema di expert witness testimony, en Rivista di Diritto Processuale, 64 (2009).

Banacloche, Julio, Diligencias preliminares (Madrid, Thomson-Civitas, 2003).

Barbosa, Juan, La negativa de la parte a someterse a una pericia médica, en Justicia, Revista de Derecho Procesal. 1-3 (2003).

Calamandrei, Piero: Derecho Procesal Civil, Tomo III (traducción de Santiago Sentis Melendo, Buenos Aires, Editorial Ejea, 1986). 
Carrara, Antonio, Prova e convincimento del giudice nel processo civile, en Rivista di Diritto Processuale, 1 (2003).

CarrasCo, Jaime, La rebeldia en el proceso civil y laboral chileno. Análisis de la rebeldía en los procedimientos ordinario, sumario, ejecutivo y laboral (Santiago, Abeledeo Perrot-LegalPublishing, 2010).

Carratta, Antonio, Funzione dimostrativa della prova, en Rivista di Diritto Processuale, 56 (2001).

CARRETTA, Francesco, Deberes procesales de las partes en el proceso civil chileno: referencia a la buena fe procesal y al deber de coherencia, en Revista de Derecho Universidad Austral de Chile, 21 (2008).

CASTILlejo, Raquel, La carga de la prueba en el proceso civil por responsabilidad médica, en La Ley, 4 (2006).

Cendon, Paolo, y Ziviz, Patrizia, L' inversione dell' onore della prova nel diritto civile, en Rivista Trimestrale di Diritto e Procedura Civile 46, (1992).

Comoglio, Luigi, Ferri, Corrado, y TARuffo, Michele, Lezione sul processo civile, (Bolonia, Il Mulino, 1995).

CONTE, Mario, La prove civile (Milán, Giuffrè Editore, 2005).

Corbal, Jesús, La adquisición procesal y la carga de la prueba (Madrid, Consejo General del Poder Judicial, 1993).

Corral, Hernán, Sobre la carga de la prueba en el Proyecto de Código Procesal Civil, en Justicia Civil: perspectivas para una reforma en la legislación chilena (Maite Aguirrezabal G., Editor), Cuadernos de Extensión Jurídica 23.

CorTés, Valentín, Algunos aspectos sobre la inversión de la carga de la prueba, en Revista Iberoamericana de Derecho Procesal, 2-3 (1972).

Damaska, Mirjan, El derecho probatorio a la deriva (traducción de Joan Picó i Junoy, Madrid, Marcial Pons, 2015).

De la Prada Rodríguez, Mercedes, y Muñoz, Roberto, El proceso civil inglés (Granada, Editorial Comares, 2014).

Denti, Vittorio, L'inversione dell' prova: rilievi introduttivi, en Rivista Trimestrale di Diritto e Procedura Civile 46, (1992).

Díaz-Regañon, Calixto, El régimen de la prueba en la responsabilidad civil médica. Hechos y derecho, (Pamplona, Editorial Aranzadi, 2006).

Esteve, José, Técnica, riesgo y Derecho. Tratamiento del riesgo en el Derecho ambiental, (Barcelona, Ariel, 1999).

FERnÁNDEZ, Mercedes, La carga de la prueba en la práctica judicial civil (Madrid, Editorial La Ley, 2006).

Fabbrini, Giovanna, Note in tema di presunzioni legali, en Rivista Trimestrale di Diritto e Procedura Civile, 45 (1991).

Ferrer, Jordi, La valoración racional de la prueba (Madrid, Marcial Pons, 2009).

GASCÓn, Marina, Cuestiones probatorias (Bogotá, Universidad Externado Colombia, 2012).

Goldschmidt, James, Teoría general del proceso (Barcelona, Editorial Labor, 1936).

GonzÁlez, Daniel, Quaestio Facti. Ensayos sobre la prueba, causalidad y acción (Bogotá, Temis, 2005).

GONZÁLEZ, Piedad, Los criterios de disponibilidad y facilidad probatoria en el sistema del artículo 217 de la LEC, en Carga de la prueba y responsabilidad civil (Valencia, Tirant lo Blanch, 2007).

Hollander, Charle, Documentary disclosure: lessons from the English experience, en In 
The Future of Transnational civil litigations (Londres, Britisch Institute of International and Comparative Law, 2004).

HunTER, Iván, No hay buena fe sin interés: La buena fe procesal y los deberes de veracidad, completitud y colaboración, en Revista de Derecho de la Universidad Austral de Chile, 21 (2008).

IgARTUA, Juan, Valoración de la prueba, motivación y control en el proceso penal (Valencia, Tirant lo Blanch, 1994).

IGLESIAS, Inés, Intervenciones corporales y prueba de ADN: libre valoración probatoria y argumentación jurídica, en García Amado y Bonorino, Pablo (Coords.) Prueba y razonamiento probatorio en Derecho, Debates sobre abducción, (Granada, Comares, 2014).

JimÉnEz Bautista, Susana, La buena fe: perspectiva doctrinal, legal y jurisprudencial. Examen del artículo 247 de la vigente Ley de Enjuiciamiento Civil, en Revista Jurídica Española de doctrina, jurisprudencia y bibliografia, 4 (2003).

LozANo-Higuero, Manuel, La buena fe procesal: consideraciones doctrinales y jurisprudenciales, en El abuso del proceso: mala fe y fraude de ley procesal, (Madrid, Consejo General del Poder Judicial, 2006).

LunA, Álvaro, La prueba de la responsabilidad civil médico-sanitaria. Culpa y causalidad (Madrid, Thomson Civitas, 2004).

Maturana, Javier, Sana Crítica. Un sistema de valoración racional de la prueba (Santiago, Thomson Reuters, 2014).

Michelli, Gian, La carga de la prueba (traducción de Santiago Sentis Melendo, Bogotá, Temis, 2004).

MonTERo Aroca, Juan, Ideología y proceso civil. Su reflejo en la buena fe procesal, en El abuso del proceso: mala fe y fraude de ley procesal, (Madrid, Consejo General del Poder Judicial, 2006).

Montero, Juan, La Prueba en el Proceso Civil (Navarra, Thomson-Reuters, 2005).

MontesAno, Luigi, La garanzia costituzionale del contraddittorio e i giudizi civile di 'terza via', en Rivista di Diritto Processuale, 55 (2000).

Muñoz, Luis, Técnica probatoria. Estudios sobre las dificultades de prueba en el proceso (Bogotá, Temis, 1997).

Nieva, Jordi, La duda en el proceso penal (Madrid, Marcial Pons, 2013).

Nieva, Jordi, La duda en el proceso penal (Madrid, Marcial Pons, 2013).

Nieva, Jordi., Enjuiciamiento prima facie, (Barcelona, Atelier, 2007).

Orellana, Fernando y Pérez RagOne, Álvaro, Radiografía de la rebeldia en el proceso civil: tópicos hacia una adecuada regulación en la nueva justicia civil, en Ius et Praxis, 12 (2007).

Ormazabal, Guillermo, Carga de la prueba y sociedad en riesgo (Madrid, Marcial Pons, 2004).

Palomo, Diego, Las cargas probatorias dinámicas: ¿Es indispensable darse toda la vuelta, en Revista Ius et Praxis, 19 (2013).

PATTI, Salvatore, Libero convincimento e valutazione delle prove, en Rivista di Diritto Processuale, 38 (1983).

PELAYO, Ángel, El derecho a la autonomía del paciente en la relación médica. El tratamiento jurisprudencial del consentimiento informado (Granada, Editorial Comares, 2009).

Pereira, Silvia La exhibición de documentos y soportes informáticos en el proceso civil (Navarra, Thompson Reuters, 2013).

PEYRANO, Jorge, La doctrina de las cargas probatorias dinámicas y la máquina de impedir 
en materia jurídica, Peyrano, Jorge (director), Cargas probatorias dinámicas (Buenos Aires, Rubinzal-Culzoni, 2004).

Peyrano, Jorge, Nueve lineamientos de las cargas probatorias dinámicas, Peyrano, Jorge (director), Cargas probatorias dinámicas (Buenos Aires, Rubinzal-Culzoni, 2004).

RiccI, Gian, Prove e argomenti di prova, en Rivista Trimetrale di Diritto e Procedura Civile, 47 (1988).

RuFFINI, Giuseppe, Argomenti di prova e fondamento della decisione del giudice civile, en Rivista Trimetrale di Diritto e Procedura Civile, 58 (2004).

SÁnchez, Pedro, La prueba por presunciones. Particular referencia a su aplicación judicial en supuestos de responsabilidad extracontractual (Granada, Comares, 2007).

Scalamogna, Margherita, L'efficacia probatoria degli argomenti di prova, en Rivista di Diritto Processuale, 64 (2005).

SCHauer, Frederick, Pensar como un abogado. Una nueva introducción al razonamiento jurídico (Madrid, Marcial Pons, 2013).

STÜRner, Rolf, Derecho Procesal y culturas jurídicas en Ius et Praxis 13 (2007).

TARUFFO, Michele, El proceso civil adversarial en la experiencia americana. El modelo americano del proceso de connotación dispositiva (Bogotá, Temis, 2008).

Taruffo, Michele, La prueba (Madrid, Marcial Pons, 2008).

TARUfFo, Michele, La prueba de los hechos (Madrid, Trotta, 2009).

TARUfFo, Michele, Páginas sobre la justicia civil (traducción de Maximiliano Aramburo, Madrid, Marcial Pons, 2009).

Taruffo, Michele, Presunzioni, inversioni, prova del fatto, en Rivista Trimestrale di Diritto e Procedura Civile 46 (1992).

Vallejos, Juan, El abuso del proceso en materia probatoria, en XXI Congreso Nacional de Derecho Procesal, Tomo I, (San Juan, Universidad Católica del Cuyo, 2001).

VAlLote, Daniel, Abuso del proceso por las partes, presupuestos generales, en XXI Congreso Nacional de Derecho Procesal, Tomo I, (San Juan, Universidad Católica del Cuyo, 2001).

VERdE, Giovanni, L'inversione degli oneri probatori nel processo, en Rivista Trimestrale di Diritto e Procedura Civile 46 (1992).

Weigmann, Roberto, L' inversione dell' onore della prova nel diritto commerciale, en Rivista Trimestrale di Diritto e Procedura Civile, 46 (1992). 